\title{
The Effects of Adversity on Depression among University Students
}

\author{
Paul A. Muller \\ Department of Sociology and Criminal Justice, University of Mount Union \\ Email:mullerpa@mountunion.edu
}

\section{Doi:10.5901/jesr.2016.v6n2p53}

\begin{abstract}
Based on secondary analysis of data from a sample of 649 individuals attending one of three New England colleges in the United States, this study examines the links between childhood adversity and young adult depression. Assessment of the relative impact on depression of adversity experienced directly and adversity experienced indirectly through family problems was made in an attempt to identify mechanisms by which each affects psychological distress. It was hypothesized that childhood adversity exhibits effects on psychological distress in young adulthood, at least in part, through its damaging impact on the development of social and personal resources-specifically, by affecting a reduction in family support, peer support, self-esteem, and mastery. Further, it was hypothesized that the importance of these mediators in explaining the link to depression of adversity differs between personal problems and family problems. Findings indicate that family adversity has a more severe impact on young adult depression than personal adversity. Further, the two most important mediators of the relationship to depression of family adversity are self-esteem and mastery, but the two most important mediators of the relationship to depression of personal adversity are self-esteem and family support. Also, the combined mediating effect of the resource variables is greater for family adversity than it is for personal adversity. These findings suggest that the mechanisms involved in the translation of stress to depression do vary somewhat between adversity that is experienced directly and adversity that is experienced indirectly through the family.
\end{abstract}

Keywords: stressors, depression, social resources, personal resources

\section{Introduction}

While all of the incidents and conditions contained on most life event checklists can be said to assess personal exposure to stress, some adversities are likely more self-experienced (or directly experienced by the individual) than others. For example, being hospitalized with a serious illness is, arguably, a more directly-experienced ordeal than having an intimate hospitalized with a serious illness. It is admittedly difficult, if not impossible, to entirely differentiate between hardships that are experienced directly and those that are experienced indirectly. Many traumas and adversities have components or aspects that affect individuals both directly and indirectly. To the extent that the overlap between direct experience and indirect experience is a matter of degree, however, it seems possible to group stressors by their tendency to affect through mostly one or the other. For example, having to repeat a grade at school is a rather directlyexperienced hardship. However, while having a parent sent to prison may be experienced as a "direct" loss by a child, much of its negative impact is likely a function of the family problems generated by the event. The distinction made in the present study is between hardships that are likely experienced more directly by the child (even if other family members were also possibly affected), versus those that are likely experienced more indirectly through the difficulties and problems of family members. Distinguishing between direct and indirect experience of adverse events and circumstances may have important implications for related outcomes.

\section{Literature Review}

Past research has demonstrated the negative impact that many directly-experienced adversities can have on subsequent well-being. For example, children who experience chronic illness are far more likely than their healthy counterparts to receive at some point during their youth a psychiatric diagnosis (Drotar, 2006; Drotar \& Bush, 1985). Research has also demonstrated a negative impact on well-being of direct exposure to disastrous events. Natural disasters have been shown to adversely affect children in a variety of ways, including increased likelihood to experience posttraumatic stress disorder both in the short-term and long-term (e.g., Lai et al., 2013; LaGreca et al., 1996). Children who experience academic difficulties and failures, such as failing a grade at school, are at greater risk for anxiety and depression (Masten 
et al., 2005; Hilsman \& Garber, 1995).

While there is substantial evidence that directly-experienced stressors adversely affect mental health, events and conditions that disturb social networks--and are thereby experienced more indirectly--are also important sources of adversity in childhood. Family-related adversities may be an especially problematic type of indirectly-experienced stressor. For example, events such as divorce may often represent a major stressor in the lives of children. Strohschein (2005) found evidence that children of divorced parents are more likely to experience subsequent internalized problems such as anxiety and depression. Children of alcoholic parents have been shown to be at elevated risk for depression even into adulthood (Anda et al., 2002).

The studies mentioned here demonstrate that both experiencing adversity directly and experiencing adversity indirectly through family problems or dysfunction can negatively affect well-being. Although studies have not explicitly compared these two domains of stress, it seems plausible that they may differ in their long-term effects on well-being. Moreover, it is likely that the processes by which long-term mental health consequences occur vary by these two forms of stress. In other words, the mediators (or the power of a given mediator) involved in the translation of stress to depression may be different depending on stress type. This is due to the possibly dissimilar impact(s) that stressors can have on various social and personal resources. Making comparisons in the relative impact on depression of experiencing adversity directly and experiencing adversity indirectly through the family not only helps identify variations in potency, but it also allows the specification of different pathways and processes by which adversity influences mental health. The present study considers the possible mediating influence of family support, peer support, mastery, and self-esteem.

While there is little doubt that social support from family and peers is beneficial to psychological well-being, both directly and as a buffer against stress, some investigators have also noted that social support may itself be affected by traumas and adversities (Turner \& Butler, 2003). For example, some stressors may represent for children the actual diminishment or loss of support resources, such as in cases of parental divorce or separation. Other hardships likely upset the quality of interactions that one is able to develop and maintain with others, effectively reducing perceived support. If traumas and adversities affect the development and maintenance of supportive networks (both familial and peer), and the resulting lower levels of support help explain subsequent depression, then social support is a mediator by which exposure to childhood adversity results in depression in young adulthood.

Similarly, while self-esteem appears to contribute to well-being (both directly and as a moderator of stress), there is reason to believe that experiencing adversities in childhood may inhibit the development of self-esteem. An individual's level of self-esteem is believed to arise in part out of social processes and contexts (Turner \& Roszell, 1994). In other words, social environments and experiences play a role in the development of self-esteem, and so it seems likely that hardships experienced in childhood would adversely affect the development of high self-esteem. Furthermore, it is reasonable to suppose that difficult events and circumstances in childhood would similarly affect one's subsequent development of feelings of mastery. Indeed, many studies of the negative outcomes associated with childhood adversity suggest a reduction in feelings of efficacy (e.g., Turner et al., 2015). If the development and maintenance of self-esteem and mastery are ongoing processes subject to external forces, then it is reasonable to suppose that they can be diminished by stressful events and circumstances, including adversities that are directly experienced by the child and adversities that are experienced more indirectly through family problems. And if lower levels of self-esteem and mastery help explain subsequent depression, then they are mediators by which childhood adversity results in depression.

The primary objective of the present study is to examine the links between childhood adversity and young adult depression. Assessment of the relative impact on depression of adversity experienced directly and adversity experienced indirectly through family problems will be made in an attempt to identify mechanisms by which each affects psychological distress. It is believed that childhood adversity exhibits effects on psychological distress in young adulthood, at least in part, through its damaging impact on the development of social and personal resources-specifically, by affecting a reduction in family support, peer support, self-esteem, and mastery. Further, it is believed that the importance of these mediators in explaining the link to depression of adversity differs between personal problems and family problems.

\section{Research Methods}

\subsection{Sample}

This study represents secondary analysis of a survey, "Childhood Adversity and the Mental Health of Adults," funded by the National Institute of Mental Health (R03\#MH56169; Heather Turner, Principle Investigator). It is based on a sample of 649 individuals attending one of three colleges in the New England area. These include: a university comprised largely 
of White, middle class students, many of whom come from small, semi-rural communities; a state college consisting of a mixture of working class White, Hispanic, African-American, and Asian students living in a medium-sized urban community; and an inner-city community college consisting of mostly lower-income African-American and Hispanic students who live in a large urban center.

Twenty percent of the sample is non-White and $40 \%$ of respondents came from households where the main provider had less than a college degree. The sample included students ranging in age from 18 to 29 , although $95 \%$ of the sample is under 25 (median age $=19$ years). The sample is $41 \%$ male and $59 \%$ female. The majority of the sample (approximately 65\%) was obtained through a random sample of student registration directories. The response rate for this part of the sample was $86 \%$. The sample also includes students who were recruited through a variety of college classes within the Liberal Arts. Response rates within classes ranged from 60\% to $95 \%$.

\subsection{Measures}

Symptoms of depression were assessed by the Center for Epidemiologic Studies Depression Scale (CES-D). Respondents indicated how often over the preceding two weeks they had experienced each of 20 symptoms on a 4-point scale ranging from 0 (rarely or none of the time) to 3 (most or all of the time). The specific items that constitute this measure are presented in Appendix A. A summary of the 20 items was constructed. The validity and reliability of this scale are well established (Radloff, 1977). In the present study, the reliability coefficient for the CES-D is .89.

Adversity in childhood was assessed using measures designed to detect the extent to which subjects were exposed to traumatic experiences, both those that were experienced directly and those that were experienced through family problems (see Appendix A, Table A1). Respondents were asked whether or not they had experienced each of the adversities at any time in their life. Individual adversities were coded $0=$ never happened and $1=$ occurred one or more times. Then, a summary count of traumas was used to construct variables representing "Personal Adversity" and "Family Adversity". All reports of experiencing adversity numbering 4 or greater were collapsed into a category representing the highest level of frequency, while the four other categories ( 0 through 3 ) correspond to the actual number of adversities experienced.

Perceived family support was assessed with a modified version of the Provisions of Social Relations Scale (Turner et al., 1983). The scale was designed to reflect the "provisions" of social relationships conceptualized by Weiss (1974), which includes attachment, social integration, reassurance of worth, reliable alliance, and guidance. Individuals responded to each item (see Appendix A) on a 4-point scale ranging from "strongly disagree" to "strongly agree." A summary of the nine items was constructed. The alpha coefficient for this scale is .84 .

Eight of the nine items used to measure family support were reworded to assess attachment, social integration, reassurance of worth, reliable alliance, and guidance provided by friends rather than family (see Appendix A). As before, subjects responded to each item on a 4-point scale ranging from "strongly disagree" to "strongly agree." A summary of the eight items was constructed, and the alpha coefficient for this scale is .91.

Self-esteem was measured with a summary score of an instrument developed by Rosenberg (1965). This scale is well established in the literature. It is composed of seven items reflecting different "self-statements," or beliefs (items presented in Appendix A). Respondents rate each statement on a 5-point scale ranging from strongly agree to strongly disagree. The internal reliability for this scale is .81 .

Mastery was assessed using the summary score of an eight-item scale developed by Pearlin and Schooler (1978). Respondents rated each item of a 4-point scale ranging from strongly agree to strongly disagree. This scale has also been used successfully in numerous studies, and its psychometric properties are well established. The exact wording of each item is presented in Appendix A. In the present study the alpha coefficient is .71.

\section{Analysis Results}

\subsection{Descriptive Analyses}

Given favorable response rates and success in identifying and recruiting respondents with varied socio-demographic characteristics, the sample is reasonably representative of a diverse New England college population. Both face-to-face and telephone interview modes were used (18\% in-person; 82\% telephone). Table 1 shows key demographic characteristics of the group of respondents. 
Table 1. Sample Characteristics

\begin{tabular}{lcc}
\hline & Frequency & Percent \\
\hline Age & 163 & \\
18 & 174 & 25.3 \\
19 & 139 & 27.0 \\
20 & 67 & 21.5 \\
21 & 102 & 10.4 \\
$22+$ & & \\
Sex & 263 & 40.5 \\
Males & 386 & 59.5 \\
Females & & \\
Race & 519 & 80.0 \\
White & 130 & 20.0 \\
Non-white & & \\
Parental education & & \\
Less than college degree & 253 & 39.5 \\
Associate degree or greater & 387 & 60.5 \\
\hline
\end{tabular}

\subsection{Regression Analyses}

Table 2 shows results from a set of hierarchical regression analyses. This method was used because it provides the ability to test for the independent effect on depression of one type of adversity (personal problems) while controlling for the effect of the other type of adversity (family problems). This method also provides the ability to reveal the mediating effect of variables by detecting the extent to which they attenuate the strength in relationship between antecedents and outcomes. In Step 1, depression is regressed on personal adversity, family adversity, and the demographic variables. Results indicate that both directly-experienced adversities and adversities experienced indirectly through family problems are significant independent predictors of depression. As expected, family adversity has a stronger relationship to depression $(B=.226, p<.001)$ than does personal adversity $(B=.106, p<.05)$.

In step 2 , family support is added to the regression equation. Family support is directly related to depression $(b=$ .156, $B=-.099, p<.05)$, such that higher levels of family support predict lower levels of depression. Adding family support also affected a small reduction in strength of relationship to depression of both personal adversity (by 11\%) and family adversity (by 6\%). Though each type of stress remains a significant predictor of depression, this attenuation in strength is evidence of a modest mediating influence by family support.

In Step 3, peer support is added (separately) to the regression equation. As with family support, there is a negative relationship between peer support and depression $(b=-.302, B=-.182, p<.001)$. Adding peer support, however, has virtually no effect on the relationships to depression of personal adversity or family adversity, and therefore exhibits no mediating effect. As shown in Step 4, when self-esteem is added to the regression equation, it has the strongest direct relationship to depression $(b=-.518, B=-.330, p<.001)$ of the four resource variables (when each is considered separately). It is also the most influential single mediator among the four resource variables. Adding selfesteem reduces the effect that personal adversity has on depression by $11 \%$, and the effect that family adversity has on depression by 29\%. In Step 5, mastery is added separately to the regression equation. Mastery is directly related to depression $(b=.454, B=-.268, p<.001)$. Its addition produces little reduction in strength of relationship to depression of personal adversity, but a moderate reduction in strength of family adversity (17\%).

Table 2. Hierarchical Regression of Depression on the Predictor Variables: Personal Adversity and Family Adversity (Standardized Coefficients in Parentheses)

\begin{tabular}{lcccccc}
\hline & Step 1 & Step 2 & Step 3 & Step 4 & Step 5 & Step 6 \\
\hline Age & $.326^{\star *}$ & $.319^{\star *}$ & $.242^{\star}$ & $.275^{\star *}$ & $.278^{\star \star}$ & $.243^{\star}$ \\
& $(.118)$ & $(.116)$ & $(.088)$ & $(.100)$ & $(.101)$ & $(.088)$ \\
Sex & .844 & .918 & $1.134^{*}$ & .620 & $1.059^{\star}$ & .846 \\
Race & $(.067)$ & $(.073)$ & $(.090)$ & $(.049)$ & $(.084)$ & $(.067)$ \\
\hline
\end{tabular}




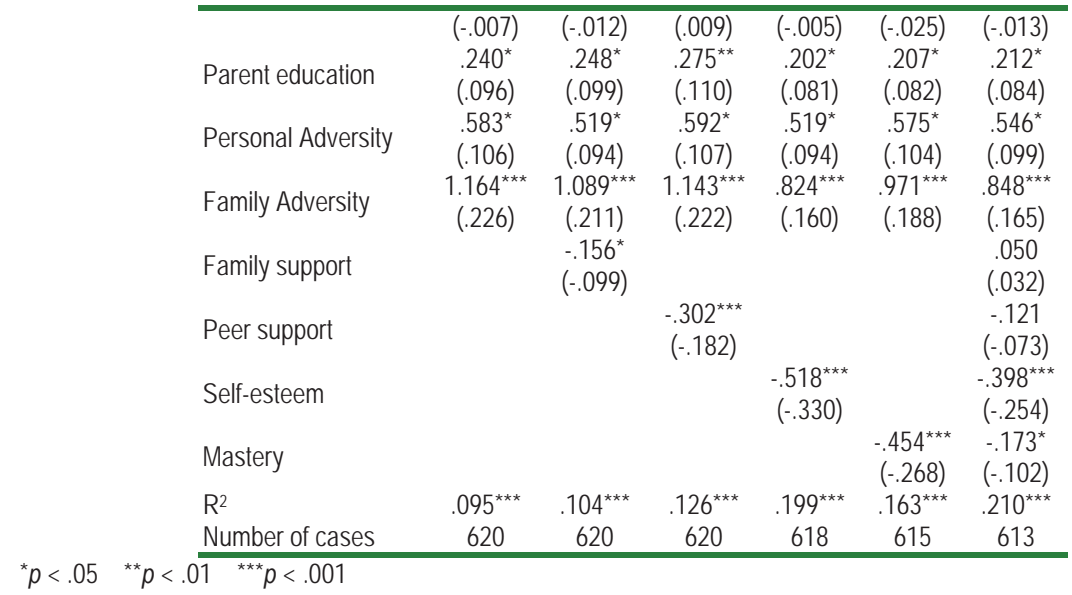

In all, the two most important mediators of the relationship to depression of personal adversity are family support and self-esteem, both affecting $11 \%$ reductions. The two most important mediators of the relationship to depression of family adversity are self-esteem and mastery (affecting $29 \%$ and $17 \%$ reductions, respectively). It is also interesting to note that self-esteem affected a much larger reduction in strength of relationship to depression of family adversity (by 29\%) than of personal adversity (by 11\%), as did mastery, though on a smaller scale (by $17 \%$ and $1 \%$, respectively). These findings provide some evidence that the importance of mechanisms involved in the translation of stress to depression varies by type of stress.

To test for their independent effects on depression and their combined mediating effect on the relationships to depression of each of the two stressor domains, all four resource variables were entered into the regression equation concurrently (Step 6). Both self-esteem and mastery remain significantly related to depression $(b=-.398, B=-.254, p<$ $.001 ; b=-.173, B=-.102, p<.05$, respectively), whereas family support and peer support do not. In other words, family support and peer support are not directly related to depression independent of self-esteem and mastery. The combined mediating effect of the four resource variables on the relationships to depression of the two stressor domains is greater for family adversity (27\% reduction) and smaller for personal adversity (6\% reduction). The full model accounts for $21 \%$ of the variance in depression.

\section{Discussion}

One of the major objectives of this study was to examine the relative impact on young adult depression of two different types of childhood adversity. To that end, a series of hierarchical regression analyses were performed. These demonstrated that both personal adversity and family adversity affect later well-being. Adversity experienced indirectly through family hardships, however, has a more severe impact on young adult depression than does directly experienced personal adversity. This is not surprising, given that family-related problems may take a heavier toll on later well-being than hardships that--although experienced directly--do not interfere as much with family functioning. For example, although being hospitalized with an illness would no doubt affect a child's well-being, the greater and more complex problems created by a comparable hospitalization of the child's parent (e.g., financial distress, increased likelihood to employ dysfunctional parenting practices), would likely produce worse consequences. Because it is in the family that young persons must exist and develop--indicating not only a quantity of involvement, but also a quality--family hardships no doubt create a deleterious milieu from which members cannot easily escape.

Another major objective of this research was to examine the mediating influences of social and personal resources on the relationships to depression of the different types of stress. Findings revealed that, in general, the mediating influences were relatively small. There could be several reasons for this. Perhaps other factors, not examined in the present study, are operating to mediate the relationship between childhood adversity and young adult depression. For example, it is likely that early adversity affects later well-being in part through a reduction in educational attainment (Chen \& Kaplan, 2003). Because the current sample includes only individuals enrolled in college, and thereby excludes those whose non-attendance may be a result of experiencing adversity, it is difficult to determine the effects of adversity on 
educational attainment among these subjects. This makes an assessment of the mediating effect of educational attainment unfeasible. Additionally, it could be that these types of childhood adversity have long-term direct effects on depression. Much literature suggests that exposure to childhood adversity predicts both short- and long-term mental health problems. For example, children of alcoholic parents have been shown to be at elevated risk for depression in childhood and adulthood (Anda et al., 2002). It could be that depressive symptomatology immediately resulting from exposure to adversity continues into adulthood.

Although the mediating influences of the resource variables on the relationships to depression of the stressor domains were relatively small, some interesting patterns did emerge. The two most important mediators of the relationship to depression of family adversity are self-esteem and mastery. That these elements of self-concept more prominently mediate the relationship between family adversity and depression than do family support and peer support is evidence of the substantial impact that family-related troubles have on children's developing sense of self. It has been argued that experiences in the family are in large part responsible for the development of self-concept. Adversities that interfere with the proper functioning of the family create an environment that inhibits the proper development of beneficial personality characteristics. This is supported by numerous studies demonstrating that children who are exposed to family-related troubles experience lower levels of self-esteem and mastery (e.g., Wilburn \& Smith, 2005; Roosa et al., 1988; Clair \& Genest, 1987). Findings here suggest that reductions in self-esteem and mastery are also partly the means by which family-related adversities in childhood affect young adult depression.

The two most important mediators of the relationship to depression of personal adversity are family support and self-esteem. Perhaps reductions in family support offers a better explanation of the relationship between personal adversity and depression than does reductions in peer support because these types of directly-experienced adversities affect the permanent relationships you have with your family more than they affect your ability to garner future support from peers. It has been argued that some personal adversities experienced in childhood can be a source of irritation for parents (e.g., academic failure), resulting in reductions in supportive behavior. This may establish a pattern of parentchild interactions characterized by lower support that continues into adulthood. The ability to establish supportive relationships with others, however, could remain unaffected. Perhaps reductions in self-esteem offers a better explanation of the relationship between personal adversity and depression than does reductions in mastery because experiencing adversities directly causes you to doubt your self-worth more than it causes you to doubt your ability to control future events and circumstances. For example, having to repeat a grade is more likely to produce feelings of incompetence than it is feelings of inevitability. Experiencing frequent teasing and harassment due to religion, sexual orientation, or physical appearance is more likely to create feelings of inferiority than it is feelings of inefficacy.

These findings--that the two most important mediators of the relationship to depression of family adversity are selfesteem and mastery, and the two most important mediators of the relationship to depression of personal adversity are family support and self-esteem--suggest that different mediators matter more or less depending on the type of stress considered. Further, the combined mediating effect of the resource variables is smaller for personal adversity than it is for family adversity. Because this suggests that the selected mediators explain the effect on depression of one type of stress better than the other, it is more evidence that the mechanisms involved in the translation of stress to depression vary somewhat by stress type.

\section{Conclusion}

In conclusion, this study contributes to an improved understanding of several issues related to childhood adversity and young adult depression. It has revealed variations in the impact on depression of different types of adversity. It has also demonstrated that the pathways by which childhood adversity affect depression may be different depending on the type of adversity to which one is exposed. Young adult mental health is an important issue. As stated by Chen and Kaplan (2003), "The peak onset of mental disorders...is between adolescence and young adulthood, and the prevalence of mental disorders among this age group is startling" ( $p$ 111). Because earlier mental health is an important predictor of later mental health, young adult depression matters not only for current well-being, but has important implications far beyond young adulthood. The current study could have intervention implications and would benefit from a programbased assessment. If, for example, if reduced mastery is key to understanding the relationship between family adversity and depression, and reductions in family support is key to understanding the relationship between personal adversity and depression, then intervention strategies intended to help those who experience these specific types of adversity could benefit from this knowledge. Perhaps counseling offered victims could be designed to emphasize the development of feelings of self-efficacy or the fostering of healthy family relations, respectively. Indeed, if variations in the causal 
pathways by which childhood adversity affects young adult well-being can be more clearly identified, then resources and services aimed at helping those exposed to adversities can be allocated with more precision and to greater effect.

\section{References}

Anda, R. F., Whitfield, C. L., Felitti, V. J., Chapman, D., Edwards, V. J., Dube, S. R., \& Williamson, D. F. (2002). Adverse childhood experiences, alcoholic parents, and later risk of alcoholism and depression. Psychiatric services, 53(8), 1001-1009.

Chen, Z., \& Kaplan, H. B. (2003). School failure in early adolescence and status attainment in middle adulthood: A longitudinal study. Sociology of Education, 76, 110-127.

Clair, D., \& Genest, M. (1987). Variables associated with the adjustment of offspring of alcoholic fathers. Journal of Studies on Alcohol, $48,345-355$.

Drotar, D. (2006). Psychological interventions in childhood chronic illness. Washington, DC: American Psychological Association.

Drotar, D., \& Bush, M. (1985). Mental health issues and services. In H. Hobbs \& J. M. Perrin (Eds.), Issues in the care of children with chronic illness (pp. 514-550). San Francisco: Jossey-Bass.

LaGreca, A., Silverman, W., Vernberg, E., \& Prinstein, M. (1996). Symptoms of posttraumatic stress in children after Hurricane Andrew: A prospective study. Journal of Consulting and Clinical Psychology, 64, 712-713.

Lai, B. S., La Greca, A. M., Auslander, B. A., \& Short, M. B. (2013). Children's symptoms of posttraumatic stress and depression after a natural disaster: Comorbidity and risk factors. Journal of affective disorders, 146(1), 71-78.

Pearlin, L. I., \& Schooler, C. (1978). The structure of coping. Journal of Health and Social Behavior, 19, 2-21.

Radloff, L. (1977). The CES-D scale: A self-report depression scale for research in the general population. Applied Psychological Measurement, 1, 385-401.

Roosa, M. W., Sandler, I. N., Beals, J., \& Short, J. L. (1988). Risk status of adolescent children of problem drinking parents. American Journal of Community Psychology, 16, 225-239.

Rosenberg, M. (1965). Society and adolescent self-image. Princeton, NJ: Princeton University Press.

Strohschein, L. (2005). Parental divorce and child mental health trajectories. Journal of Marriage and Family, 67(5), 1286-1300.

Turner, H. A., \& Butler, M. J. (2003). Direct and indirect effects of childhood adversity on depressive symptoms in young adults. Journal of Youth and Adolescence, 32, 89-103.

Turner, H. A., Shattuck, A., Finkelhor, D., \& Hamby, S. (2015). Effects of poly-victimization on adolescent social support, self-concept, and psychological distress. Journal of Interpersonal Violence, 30(10), 1-26.

Turner, R. J., Frankel, B. G., \& Levin, D. M. (1983). Social support: Conceptualization, measurement and implications for mental health. In J. R. Greeley (Ed.), Research in community and mental health, vol. 3 (pp. 67-110). Greenwich, CT: JAI Press.

Turner, R. J., \& Roszell, P. (1994). Psychosocial resources and the stress process. In W. R. Avison \& I. H. Gotlib (Eds.), Stress and mental health: Contemporary issues and prospects for the future (pp. 179-212). New York: Plenum.

Weiss, R. (1974). The provisions of social relationships. In Z. Rubin (Ed.), Doing unto others (pp. 17-26). Englewood Cliffs, NJ: PrenticeHall.

Wilburn, V. R., \& Smith, D. E. (2005). Stress, self-esteem, and suicidal ideation in late adolescents. Adolescence, 40(157), 33.

\section{Appendix A}

Table A1. Items used to measure depression, family support, peer support, self-esteem, mastery, personal adversity, and family adversity

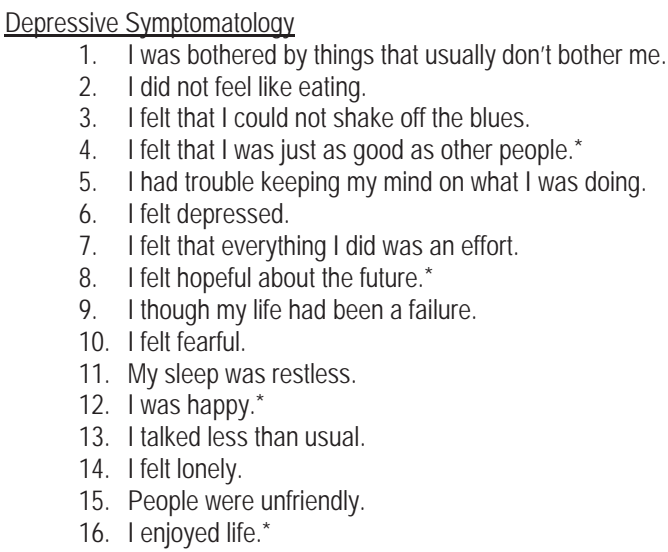


17. I had crying spells.

18. I felt sad.

19. I felt that people disliked me.

20. I could not get "going."

\section{Family Support}

1. You feel very close to your family.

2. You have family who would always take the time to talk over your problems, should you want to.

3. Your family often lets you know that they think you are a worthwhile person.

4. Your family is always telling you what to do and how to act.*

5. When you are with your family, you feel completely able to relax and be yourself.

6. No matter what happens you know that your family will always be there for you should you need them.

7. You know that your family has confidence in you.

8. You feel that your family really cares about you.

9. You often feel really appreciated by your family.

\section{Peer Support}

1. You feel very close to your friends.

2. You have friends who would always take the time to talk over your problems, should you want to.

3. Your friends often let you know that they think you're a worthwhile person.

4. When you are with your friends you feel completely able to relax and be yourself.

5. No matter what happens you know that your friends will always be there for you should you need them.

6. You know that your friends have confidence in you.

7. You feel that your friends really care about you.

8. You often feel really appreciated by your friends.

\section{Self-esteem}

1. You are able to do things as well as most other people.

2. You feel you do not have much to be proud of.*

3. You take a positive attitude toward yourself.

4. On the whole, you are satisfied with yourself.

5. You wish you could have more respect for yourself.*

6. You certainly feel useless at times. *

7. At times, you think you are a failure.*

Mastery

1. You have little control over the things that happen to you.*

2. There is really no way you can solve some of the problems you have.*

3. There is little you can do to change many of the important things in your life.*

4. You often feel helpless in dealing with problems of life.*

5. Sometimes you feel that you are being pushed around in life.*

6. What happens to you in the future mostly depends on you.

7. You can do just about anything you really set your mind to.

8. When you make plans you are almost certain you can make them work.

*These items were necessarily reverse-coded.

\section{Personal Adversity}

1. In your whole life, were you ever in a VERY SERIOUS fire, explosion, flood, tornado, hurricane, earthquake or other disaster?

2. In your whole life, were you ever in a VERY SERIOUS accident (at home, school, or in a car) where you were injured and had to be hospitalized?

3. In your whole life, did you ever have a VERY SERIOUS illness where you had to be hospitalized?

4. When you were in elementary school, junior high, or high school, did you ever have to do a school year over again?

5. When you were a child or teenager were you ever sent away or taken away from your parents for any reason?

6. In your whole life, have you ever seen a dead body in someone's house, on the street, or somewhere in your neighborhood (other than in connection with a funeral)?

7. Was there a time in your life when you were frequently teased, harassed or treated badly because of your race, nationality, or religion, or because people thought you were gay?

8. When you were a child or teenager, was there ever a time when you were frequently teased or ridiculed about your physical 
appearance because of something like a physical disability, a weight problem, or severe acne?

Family Adversity

1. At any point in your life, has someone you were really close to had a VERY SERIOUS accident where he or she had to be hospitalized?

2. At any point in your life, has someone you were really close to had a VERY SERIOUS illness where he or she had to be hospitalized?

3. When you were growing up, were there times when the main provider for your household was unemployed when he or she wanted to be working?

4. When you were a child or teenager, did either of your parents, stepparents or guardians have to go to prison?

5. When you were growing up, was there ever a time that a family member drank or used drugs so often that it caused problems?

6. When you were a child or teenager, did either of your parents, stepparents, or guardians ever have a mental illness or "nervous breakdown?"

7. Has there ever been a time when you were living with your parents or stepparents when they were always arguing, yelling, and angry at one another? 
